\title{
Welcome Frustrations with the Climate: Comment on Redclift
}

\author{
Matthias GROSS• \\ Helmholtz Centre for Environmental Research - UFZ
}

\begin{abstract}
Redclift (2011) provided a timely and perhaps deliberately provocative overview of sociological writings on climate change and the disciplinary problems of a post carbon world for environmental sociology. This comment emphasizes that he never actually clarifies what exactly are those problems that sociology faces in its attempt to open up a space for itself in the field of climate research. This omission also leads to unnecessary claims regarding the state of social science research on climate change as well as unspecified calls for more interdisciplinarity in sociological analysis of contemporary societies' carbon dependence.
\end{abstract}

Keywords: climate change, hemeneutics, interdisciplinarity, environmental sociology.

It is a great honor to be invited to comment on a paper of an eminent scholar such as Michael Redclift. Recipient of the 2006 Frederick Buttel Award from the International Sociological Association's Research Committee RC24, Environment and Society, Redclift's new paper, The Response of the Hermeneutic Social Sciences to a 'Post Carbon World', is a rather selective but neat an overview pinpointing writings on climate change and the environmental social sciences with a strong focus on environmental sociology.

The author makes transparent that the article is based on previously published sources. This is legitimate, but the overall composition also leaves the impression that the article was somewhat hastily pasted together. Despite its sometimes disjointed

\footnotetext{
E-mail: matthias.gross@ufz.de. Matthias Gross is deputy head of the Department of Urban and Environmental Sociology at Helmholtz Centre for Environmental Research, Leipzig, Germany. Cofounder and editor of the journal Nature and Culture, his recent research focuses on the sociology of alternative energy systems, the remediation of brownfield sites, and ignorance in the knowledge society. His most recent monograph is Ignorance and Surprise: Science, Society, and Ecological Design (Cambridge, MA: MIT Press, 2010). He is also editor of the Handbuch Umweltsoziologie (Wiesbaden: VS Verlag, 2011), and co-editor (with H. Heinrichs) of Environmental Sociology: European Perspectives and Interdisciplinary Challenges (Dordrecht: Springer, 2010).
} 
character, the article still reads well since it sums up and touches on many well-known debates inside and outside of environmental sociology and sociology's contributions to discussions on climate change more generally. After a first reading there is nothing to really disagree with. And exactly this appears to be a problem, a lack of edge.

From the introduction to the final section on the 'bright narrative' we find a few well known characterizations and appraisals of sociology and climate change in particular as regards questions on environmental governance, sustainable consumption, and economic development. However, if we read a little closer, the observed lack of edge may be reconsidered a bit. Indeed, already the first sentence, after reflection, can raise eyebrows: 'The environment poses real problems for the social sciences, especially the growing sense of urgency surrounding climate change', Redclift writes. What, after all are the 'real problems' that 'the environment' poses to the social sciences, and what is problematic about a 'growing sense of urgency'? The reasons listed in the following range from sociology's 'difficulties with policy agendas' and problems with 'naturalism'. However, it is not clarified why this is problematic for the social sciences in general and sociology in particular. I was expecting that Redclift, given the title of the paper, would discuss something along problems of hermeneutics in relation to debates in climate change, but this theme did not come up. As a matter of fact, the word hermeneutics is never used in the main text. There are short nods to Berger and Luckmann as well as Max Weber that could be interpreted as pointers to why this title was chosen. But this is just a (hermeneutically weak) guess.

Luckily enough (for my liking), the article thus is not about hermeneutics proper, but about sociology. However, given that sociology, as Alejandro Portes (2000) once prominently stated, has always differed from other social sciences such as economics with its focus on 'linear regularities', I do not see why an observed 'sense of urgency' about a particular environmental problem also poses a problem for sociology. Following Portes, sociology has always had 'a different, alternative vocation, defined by its sensitivity to the dialectics of things, unexpected turns of events and the rise of alternative countervailing structures' (Portes, 2000: 2-3). So why, again, has sociology any problems with climate change? Shouldn't it rather be the other way round? Now that things change rapidly and unexpectedly, political pressure shifts implications for climate and other environmental policy issues into yet unknown territory, climate change and alternative energy debates compete against each other, denial of climate change becomes a pressing issue, novel forms of political cooperation unthought-of before become a normality, and so forth, one might think that sociologists, after all, should be quite happy. Why they are not happy since, according to Redclift, they have problems does not become clear in the paper.

What is even more interesting after some reflection is that Redclift puts 'decarbonization' as an imperative prescription. There is nothing wrong with clearly taking sides or to stress the merits of one's personal beliefs, but in the article under consideration these 
statements appear as tacked onto the manuscript in a rather ad hoc fashion. The well-disposed reader would have liked to learn more about Redclift's intentions and why he sympathizes with the idea of a post carbon society, especially since his own conclusions regarding the possibility of sociology being useful to help transform modern society into its decarbonized state remain rather general and self-evident. Even more so, it remains unclear what the sociological dimensions of climate change in a 'post carbon world' are or should be, or how they differ from the contemporary 'carbon word'. Redclift, who mentions sociology's alleged rejection of ecological or biological explanations at the outset of the article, in a way naturalizes modern society's carbon dependency - as a 'given' - and simply repeats deterministic assumptions such as that of 'tipping points'. This is remarkable since toward the end of the article Redclift seems to be calling for a classical constructionist position of analyzing discourses on climate change through examination of the 'pieces ... with which such a narrative might be constructed'. The narrative that Redclift refers here is based on positively evaluated (or so it seems to me) sets of social activities by communities, individual households, or 'the brave efforts of enthusiasts' and their attempts at pushing the 'transition to a post-carbon future'.

Put this way, the paper consists of some useful reminders on contemporary discussions on climate change, but in my view it does not really add anything new to the debate. Unfortunately, this may be true to many - by far not all - sociological writings on climate change. This, indeed, is a real problem. One is tempted to state that the paper adds to the frustration that Leigh Raymond (2011) has recently uttered as regards most social science writings on climate change. Raymond observed that many commentators acknowledge the miserable state of social science research on climate change and all agree on the need for more social science in the study of climate change. However, from there on, it is hard to figure out exactly how the social sciences can constructively contribute to the debate, save for claiming they would have delivered a better understanding of some of the social or cultural factors involved. After having read Redclift's article, one is also not any wiser about a constructive or critical role of sociology in climate debates beyond the (implicit) claim that the discipline would have something to offer if only their members would be heard. At the beginning of the article, Redclift wets appetite to learn more on what he calls a 'broader interdisciplinary perspective' as a path to the contribution of sociology. Unfortunately, this issue is also not really taken up later in the article. However, I believe here we find the greatest challenge, at least for some sociologists: the interdisciplinary potential of (environmental) sociology. Environmental sociology, from its earliest incarnations as human ecology in the beginning of the $20^{\text {th }}$ century (Richards, 1907) to more current developments, surely had many interdisciplinary meeting points with other social and natural science disciplines. Today, however, sociology appears to be too shy (or unable) to cooperate with other disciplines, as Redclift quite rightly points out when mentioning other disciplines such as human geography. Environmental sociology faces a paradox. On the one 
hand, inter- or even transdisciplinarity is called for to foster integrative forms of research, in order to comprise different methods for relating new types of scientific knowledge for analysis and problem-solving. Already Riley Dunlap and William Catton's call for a New Ecological Paradigm in the 1970s did exactly this, urge sociologists to include ecological data as independent variables for social explanations (Catton and Dunlap, 1978). However, when this actually happens in contemporary research, criticism from sociologists does not wait for long. I remember too many sociology conferences where the statement '.. but this is a-sociological' (meaning not purely social, whatever that may be) is taken as an argument per se instead of asking if that allegedly outer-sociological variable or causal explanation helps to better understand certain social phenomena. The same phenomenon I observed in many research project application and evaluation procedures. On the one hand, one increasingly hears and reads the call to more interdisciplinarity and proven relevance outside the purely academic world; on the other hand, you have the standard evaluation procedures that do de-value any interdisciplinary cooperation as not useful for the progress of sociological research and theory. Worse, any attempt to use sociology's theoretical reflections as input into pragmatic problem solution is counter argued with (in my view) worn out debates about naturalistic fallacies and the like. I guess it is along these lines that Redclift's paper can be understood as an excellent eye opener for sociologists, because it touches on many of the limitations of sociology and its potential for interdisciplinary work - this insight, however, only becomes clearer upon a closer look at the paper. Put differently, sometimes it can be insights one has to interpret into a text that appear to be most useful; insights that one nevertheless would not have gained easily without the text.

However, not every reader has a taste for accomplishing this type of interpretation, or, for that matter, much reason to do so. Consequently, I wish the author had elaborated a bit more on the relationship between institutional reform strategies within the context of, what Redclift calls, material changes. How can the two in Redclift's view be conceptually related? Furthermore, it would have been helpful if Redclift had explained a bit on how we empirically should be able to start research on 'how current behavior is tied into patterns and cycles of carbon dependence'. After all, this points to a crucial conceptual vacuum, that is, how to connect our sociological reflections with carbon cycle data.

In sum and quite paradoxically, the more critically I thought about Redclift's paper after my first readings, the more often I found his paperstimulating. More than once I found myself sitting on the couch or on the train and reflecting on post carbon society, poststructural ecology, or what actually the problem of sociology with climate change may be. Hermeneutically speaking, I as commentator developed my (provisional and incomplete) interpretations, hoping that my constructions connect to the world view that produced the article. Along those lines I sense that my immediate impression of "The Response of the Hermeneutic Social Sciences to a 'Post Carbon World" as a disjointed piece may even have been intended by such 
an eminent author as Redclift in order to get impatient commentators (like me) an easy run for some fast criticism as well as some excellent food for thought. Be that as it may, I appreciate Redclift's cordial - intended or not strategy very much.

\section{References}

Catton, W. R. and R. E. Dunlap (1978) 'Environmental sociology: A new paradigm'. The American Sociologist, 13(1): 41-49.

Portes, A. (2000) 'The hidden abode: Sociology as analysis of the unexpected'. American Sociological Review, 65(1):1-18.

Redclift, M. (this issue).

Raymond, L. (2011) “It's too late baby, now, it's too late?' Frustration and resignation in recent books on climate change policy'. Nature and Culture, 6 (2):192-203.

Richards, E.H. (1907) Sanitation in Daily Life. Boston: Whitcomb \& Barrows. 
